\title{
Vector Representation of Triadic Transformations
}

\author{
Representação vetorial de transformações triádicas
}

\author{
Carlos de Lemos Almada \\ Universidade Federal do Rio de Janeiro, Rio de Janeiro, Brazil \\ carlosalmada@musica.ufrj.br
}

\begin{abstract}
This article introduces two vectors intended to formalize some triadic transformations, considering specially the Chromatic Transformational System by David KOPP (2002). The numeric content of vector K describes concisely the processes associated to a given operation that must be applied for transforming a referential perfect triad onto a derived one. Vector $\mathrm{G}$ informs the spatial position of an operation considering its geometric projection on a referential two-dimensional plan (a Tonnetz). A practical application concerning analysis by computational means is presented in the last section of the study.
\end{abstract}

Keywords: Neo-Riemannian theory; Transformational Chromatic System; Parsimonious Voice-Leading; Vector representation; Music Analysis.

\begin{abstract}
Resumo: Este artigo apresenta dois vetores destinados à formalização de transformações triádicas, considerando especialmente o Sistema de Transformações Cromáticas proposto por David KOPP (2002). 0 conteúdo numérico do vetor $\mathrm{K}$ descreve concisamente o processo associado a uma determinada operação que deve ser aplicada para transformar uma tríade perfeita referencial em uma tríade derivada. 0 vetor G informa a posição espacial de uma operação considerando sua projeção geométrica em um plano bidimensional de referência (a Tonnetz). Uma aplicação prática relacionada a análise computacional é apresentada na seção final do artigo.
\end{abstract}

Palavras-chave:Teoria Neorriemanniana; Sistema de Transformações Cromáticas; Condução parcimoniosa de vozes; Representação vetorial; Análise musical.

Submission date: 28 July 2017

Final approval date: 29 March 2018

\section{1 - Basic principles of the Neo-Riemannian Theory}

The Neo-Riemannian theory (henceforward, NRT) is certainly one of the most attractive poles of interest for systematical studies concerned to pitch relations. Being initially formulated in the 1980s, NRT has inspired since then varied approaches and the arousal of new theoretical branches. One of them, which is adopted as the main reference in this study, was introduced by DAVID KOPP (2002): the Chromatic Transformational System. The present proposal aims at formalizing some elements and relations that form this system through vector representation, searching to provide adequate means for computer-aided analysis.

Neo-Riemannian theory arose in response to analytical problems posed by chromatic music that is triadic but not altogether tonally unified. Such characteristics are primarily identified with music of Wagner, Liszt, and subsequent generations, but are also 
represented by some passages from Mozart, Schubert, and other pre-1850 composers (COHN, 1998, p.167-8).

Accordingly, NTR aimed originally to explain certain tonal choices adopted by some 19thcentury composers, which until that moment (the end of the 20th century) were frequently viewed as merely idiosyncratic solutions, as if they purely resulted from the romantic Zeitgeist. In 1982, David LEWIN (1982) pioneered a new bias on this subject, proposing that those allegedly eccentricities or coloristic effects produced by romantic tonal relations could be interpreted as strictly functional, with the same status of those of classical harmony. In his paper, besides a detailed background about the development of NTR, COHN lists six basic concepts (derived from original formulations by Hugo RIEMANN (1849-1919) in his theory of harmonic functions $)^{1}$ that summarize and define the scope and structure of the new theory: "triadic transformations; common-tone maximization; voice-leading parsimony, 'mirror' or 'dual' inversion, enharmonic equivalence, and the 'Table of Tonal Relations'" (COHN, 1998, p.189).

COHN also summarizes the main contributions to the expansion of the scope of NRT, since Lewin's pioneering formulations, focusing especially on the improvement of Riemann' system of transformational operations. Operations can be defined as functions or algorithms that transform the content of a referential perfect triad (henceforward triad $a$ ) into a derived one (triad $b$ ), in such a manner that at least one common note of both chords is maintained during the process. The remaining note(s) of the triad $a$ must move to the triad $b$ through the shortest possible way(s), which corresponds to a parsimonious voice-leading. Riemann's original idea of triadic transformation was resumed by Lewin and became the very nucleus of NRT. Since then a number of contributions and particular approaches considering conceptualization and terminology were proposed by various authors, like Bryan HYER (1995), Peter STEINBACH and Jack DOUTHETT (1998), Dmitri TYMOCZKO (2011), Richard COHN (2012) and, specially, David Kopp, who introduced his chromatic transformational system, the main theoretical reference of this study.

\section{2 - The Chromatic Transformational System}

Kopp' system is formed by 13 classes of operations (from now on labeled as Kopp-operations or, in short, k-op), which exhaust the possibilities of connections between triads with common notes, including chromatic mediant relations (see Figure 1). ${ }^{2}$

\footnotetext{
1 Riemann's vast theoretical work encompasses a large number of volumes concerned to a wide range of subjects (rhythm and metrics, musical aesthetics, dynamics and agogic, phraseology and form, etc.) along almost 40 years. However, his most far-reaching and known studies are undoubtedly centered on the field of harmony, specifically the laws of the functional relations, developed mainly during the 1880s. For an overview of his functional theory, see RIEMANN (1896).

${ }^{2}$ In this aspect, Kopp' system differs from other theoretical proposals (like the Cohn's triplet P, L and R), since all possible common-note relations can be expressed with a unique symbol. For example, the operation $\mathbf{M}^{+}$is used for mapping $\mathrm{C}$ into $\mathrm{A} b$ (in $\mathrm{Cohn}$ 's system, the same connection demands the combination of two operations, $\mathbf{P}+\mathbf{L})$.
} 


\begin{tabular}{|c|c|c|c|c|c|c|}
\hline symbol & name & interval & mode $(\mathrm{a})$ & mode (b) & Common notes & example \\
\hline $\mathbf{I}$ & identity & unisson & $\mathrm{M} / \mathrm{m}$ & $\mathrm{M} / \mathrm{m}$ & {$[1.3 .5]=[1.3 .5]$} & $\mathrm{C} \rightarrow \mathrm{C} / \mathrm{c} \rightarrow \mathrm{c}$ \\
\hline $\mathbf{r}$ & relative & $\mathrm{m} 3(\downarrow / \uparrow)$ & $\mathrm{M} / \mathrm{m}$ & $\mathrm{m} / \mathrm{M}$ & {$[1.3]=[3.5]$} & $\mathrm{C} \rightarrow \mathrm{a} / \mathrm{c} \rightarrow \mathrm{Eb}$ \\
\hline $\mathbf{R}$ & relative & $\mathrm{M} 3(\uparrow / \downarrow)$ & $\mathrm{M} / \mathrm{m}$ & $\mathrm{m} / \mathrm{M}$ & {$[3.5]=[1.3]$} & $\mathrm{C} \rightarrow \mathrm{E} / \mathrm{c} \rightarrow \mathrm{Ab}$ \\
\hline $\mathbf{P}$ & parallel & unisson & $\mathrm{M} / \mathrm{m}$ & $\mathrm{m} / \mathrm{M}$ & {$[1.5]=[1.5]$} & $\mathrm{C} \rightarrow \mathrm{c} / \mathrm{c} \rightarrow \mathrm{C}$ \\
\hline $\mathbf{S}$ & slide & $\mathrm{m} 2(\uparrow / \downarrow)$ & $\mathrm{M} / \mathrm{m}$ & $\mathrm{m} / \mathrm{M}$ & {$[3]=[3]$} & $\mathrm{C} \rightarrow \mathrm{db} / \mathrm{c} \rightarrow \mathrm{B}$ \\
\hline $\mathbf{D}^{+}$ & dominant & $\mathrm{P} 4 \uparrow$ & $\mathrm{M} / \mathrm{m}$ & $\mathrm{M} / \mathrm{m}$ & {$[5]=[1]$} & $\mathrm{C} \rightarrow \mathrm{G} / \mathrm{c} \rightarrow \mathrm{g}$ \\
\hline $\mathbf{D}^{-}$ & dominant & $\mathrm{P} 4 \downarrow$ & $\mathrm{M} / \mathrm{m}$ & $\mathrm{M} / \mathrm{m}$ & {$[1]=[5]$} & $\mathrm{C} \rightarrow \mathrm{F} / \mathrm{c} \rightarrow \mathrm{f}$ \\
\hline $\mathbf{F}^{+}$ & five & $\mathrm{P} 4 \uparrow$ & $\mathrm{M} / \mathrm{m}$ & $\mathrm{m} / \mathrm{M}$ & {$[5]=[1]$} & $\mathrm{C} \rightarrow \mathrm{g} / \mathrm{c} \rightarrow \mathrm{G}$ \\
\hline $\mathbf{F}^{-}$ & five & $\mathrm{P} 4 \downarrow$ & $\mathrm{M} / \mathrm{m}$ & $\mathrm{m} / \mathrm{M}$ & {$[1]=[5]$} & $\mathrm{C} \rightarrow \mathrm{f} / \mathrm{c} \rightarrow \mathrm{F}$ \\
\hline $\mathbf{M}^{+}$ & cr.mediant & $\mathrm{M} 3 \downarrow$ & $\mathrm{M} / \mathrm{m}$ & $\mathrm{M} / \mathrm{m}$ & {$[1]=[3] /[3]=[5]$} & $\mathrm{C} \rightarrow \mathrm{Ab} / \mathrm{c} \rightarrow \mathrm{ab}$ \\
\hline $\mathbf{M}^{-}$ & cr.mediant & $\mathrm{M} 3 \uparrow$ & $\mathrm{M} / \mathrm{m}$ & $\mathrm{M} / \mathrm{m}$ & {$[3]=[1] /[5]=[3]$} & $\mathrm{C} \rightarrow \mathrm{E} / \mathrm{c} \rightarrow \mathrm{e}$ \\
\hline $\mathbf{m}^{+}$ & cr.mediant & $\mathrm{m} 3 \downarrow$ & $\mathrm{M} / \mathrm{m}$ & $\mathrm{M} / \mathrm{m}$ & {$[3]=[5] /[1]=[3]$} & $\mathrm{C} \rightarrow \mathrm{A} / \mathrm{c} \rightarrow \mathrm{a}$ \\
\hline $\mathbf{m}^{-}$ & cr.mediant & $\mathrm{m} 3 \uparrow$ & $\mathrm{M} / \mathrm{m}$ & $\mathrm{M} / \mathrm{m}$ & {$[5]=[3] /[3]=[1]$} & $\mathrm{C} \rightarrow \mathrm{Eb} / \mathrm{c} \rightarrow \mathrm{eb}$ \\
\hline
\end{tabular}

Figure 1: List of the k-ops, considering: symbol, name, operational interval, mode of triad a, mode of triad b, mapping of common notes and exemplification (considering $\mathrm{C}$ major and $\mathrm{C}$ minor as referential triads)

Observations:

a) By convention, capitals represent major triads and lowercase letters refer to minor triads;

b) Operation I maps a triad onto itself;

c) Operations $\mathbf{r}, \mathbf{R}$ and $\mathbf{S}$ are considered by Kopp as contextual operations, i.e. their respective intervallic directions depend on the mode of the triad $a$;

d) Besides these, operations $\mathbf{P}$ and $\mathbf{F}$ express the dual nature of the Riemannian theory, since their application imply in change of mode of the referential triad;

e) Operations $\mathbf{r}, \mathbf{R}, \mathbf{S}$ and $\mathbf{P}$ are considered commutative, i.e., their recursive application return the original triad;

f) The superscripts "+" and "-" added to operations D, F, $\mathbf{M}$ and $\mathbf{m}$ indicate, respectively, main and secondary directions of the corresponding intervals;

g) The connection of triads without common notes (or disjunct relations) must necessarily involve application of two combined k-ops. Figure 2 presents some of the various possibilities to transform $\mathrm{C}$ onto eb.

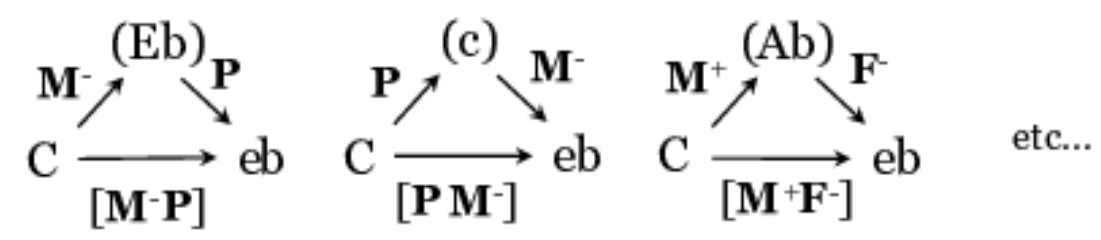

Figure 2: Three possible connections between the disjunct triads $\mathrm{C}$ and $\mathrm{e} b$ through employment of two combined k-ops.

\section{3 - Vector formalization}

This section presents a proposal for a vector formalization of part of NRT, considering two correlated elements: the group of Kopp's operations and the specific spatial orientations of their projections on a Tonnetz. 


\section{1 - Vector $\mathrm{K}$}

A vector $\mathrm{K}$ corresponding to a given $\mathrm{k}$-op consists of an ordered sequence of codified data that describes the process of transformation of a referential triad $a$ into a derived triad $b$. It is formed by eight entries distributed into three regions (i, ii, iii), each one destined to present some specific information (Figure 3): (i) entries 1-2, representing the modes of triads a and b; (ii) entries 3-5, representing common note(s) maintained in the triad a, considering its normal form, root (a1), third (a3) and fifth (a5); (iii) entries 6-8, representing common note(s) maintained in the triad b, considering its normal form, root (b1), third (b3) and fifth (b5).

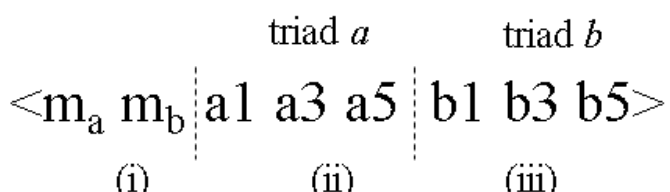

(i)

(ii)

(iii)

Figure 3: Generic structure of the vector K: (i) mode of triad $a\left(\mathrm{~m}_{\mathrm{a}}\right)$ and mode of triad $b(\mathrm{mb})$; (ii) normal form of triad $a$ (a1-a3-a5); (iii) normal form of triad $b$ (b1-b3-b5).

The content of vector $\mathrm{K}$ is expressed in binary format according to the following conventions:

- $\quad$ region (i): " 1 " represents the minor mode and " 0 " the major mode;

- regions (ii) and (iii): "1" represents maintenance of a given note/position and "0" its absence.

The elements in regions (ii) and (iii) are mutually complementary; in other words, a "1" in a given position in region (ii) will be always mapped onto a "1" in region (iii), at the same or other relative position, depending on the involved k-op. Figure 4 shows the corresponding vector $\mathrm{K}$ of the operation $\mathbf{D}^{+}$(formally identified as $\mathrm{K}_{\mathrm{D}+}$ ) considering as example the connection between the triads $\mathrm{C}$ and $\mathrm{F}$. As it can be observed, the maintenance of the unique common note between both chords (pitch-class 0 ) is registered by the "1s" at positions 5 (a1) and 8 (b5).

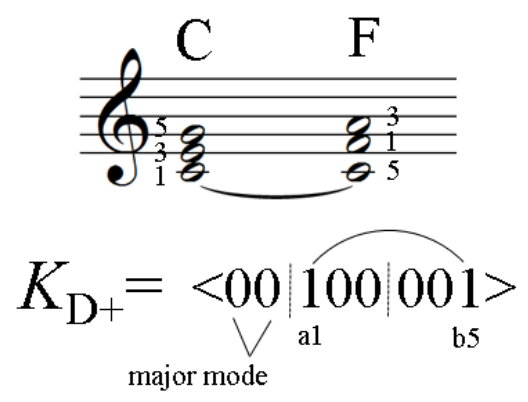

Figure 4: Structure of vector $\mathrm{K}$ of the operation $\mathbf{D}^{+}$, taking as example the harmonic progression C-F.

Since the content of $\mathrm{K}$ is a binary-coded number, it is possible to transcribe it in decimal format, a number that represents a univocal and precise identifier for a k-op, being henceforward labeled as "kc" (kopp-code). Figure 5 presents the complete K system. While the number of operations is 13 , there are 26 associated vectors, due to the fact that the application of a given 
operation to a referential major triad produces a different result if compared with the same operation applied to a minor chord.

\begin{tabular}{|c|c|c|c|c|}
\hline k-op & Tr.1 & Tr.2 & K & kc \\
\hline I & C & C & $<00111111>$ & 63 \\
\hline I & c & c & $<1111111>$ & 255 \\
\hline r & C & a & $<01110011>$ & 115 \\
\hline r & c & Eb & $<10011110>$ & 158 \\
\hline R & C & e & $<01011110>$ & 94 \\
\hline R & c & Ab & $<10110011>$ & 179 \\
\hline P & C & c & $<01101101>$ & 109 \\
\hline P & c & C & $<10101101>$ & 173 \\
\hline S & C & db & $<01010010>$ & 82 \\
\hline S & c & B & $<10010010>$ & 146 \\
\hline $\mathrm{D}^{+}$ & C & F & $<00100001>$ & 33 \\
\hline $\mathrm{D}^{+}$ & c & f & $<11100001>$ & 225 \\
\hline $\mathrm{D}^{-}$ & C & G & $<00001100>$ & 12 \\
\hline $\mathrm{D}^{-}$ & c & g & $<11001100>$ & 204 \\
\hline $\mathrm{F}^{+}$ & C & f & $<01100001>$ & 97 \\
\hline $\mathrm{F}^{+}$ & c & F & $<10100001>$ & 161 \\
\hline $\mathrm{F}^{-}$ & C & g & $<01001100>$ & 76 \\
\hline $\mathrm{F}^{-}$ & $\mathrm{c}$ & $\mathrm{G}$ & $<10001100>$ & 140 \\
\hline $\mathrm{M}^{+}$ & $\mathrm{C}$ & $\mathrm{Ab}$ & $<00100010>$ & 34 \\
\hline $\mathrm{M}^{+}$ & $\mathrm{c}$ & $\mathrm{ab}$ & $<11010001>$ & 209 \\
\hline $\mathrm{M}^{-}$ & $\mathrm{C}$ & $\mathrm{E}$ & $<00010100>$ & 20 \\
\hline $\mathrm{M}^{-}$ & $\mathrm{c}$ & $\mathrm{e}$ & $<11001010>$ & 202 \\
\hline $\mathrm{m}^{+}$ & $\mathrm{C}$ & $\mathrm{A}$ & $<00010001>$ & 17 \\
\hline $\mathrm{m}^{+}$ & $\mathrm{c}$ & $\mathrm{a}$ & $<11100010>$ & 226 \\
\hline $\mathrm{m}^{-}$ & $\mathrm{C}$ & $\mathrm{Eb}$ & $<00001010>$ & 10 \\
\hline $\mathrm{m}^{-}$ & $\mathrm{c}$ & $\mathrm{eb}$ & $<11010100>$ & 212 \\
\hline & & & \\
\hline
\end{tabular}

Figure 5: List of the 26 possible vectors $\mathrm{K}$, considering symbol, referential and derived triads (examples in $\mathrm{C}$ and c), vector's binary content and corresponding kc

\section{2 - Vector G}

This element is associated to the geometric representation of a k-op. ${ }^{3}$ The vector G ("G" for "geographic") corresponding to a given operation informs its spatial position when projected on a Tonnetz. A specific Tonnetz was designed for this purpose, considering the following conventions (see Figure 6):

- It can be viewed as a virtually infinite cartesian plan with the horizontal axis presenting ascending major thirds (4 semitones) and the vertical axis presenting ascending minor thirds (3 semitones);

- The points on the Tonnetz represent pitch classes (pcs) in modulo 12. As it can be observed, this configuration implies periodic mapping of the total chromatic collection;

- Major and minor triads are plotted by connecting three adjacent points/pcs to form Pythagorean 5-4-3 triangles. In this manner, major and minor triads are geometrically 
distinguished by the position of their respective right angle (Figure 6 exemplifies this aspect with the triads $C(0,4,7)$, as a grey triangle, and c $(0,3,7)$, as a white one $)^{3}$

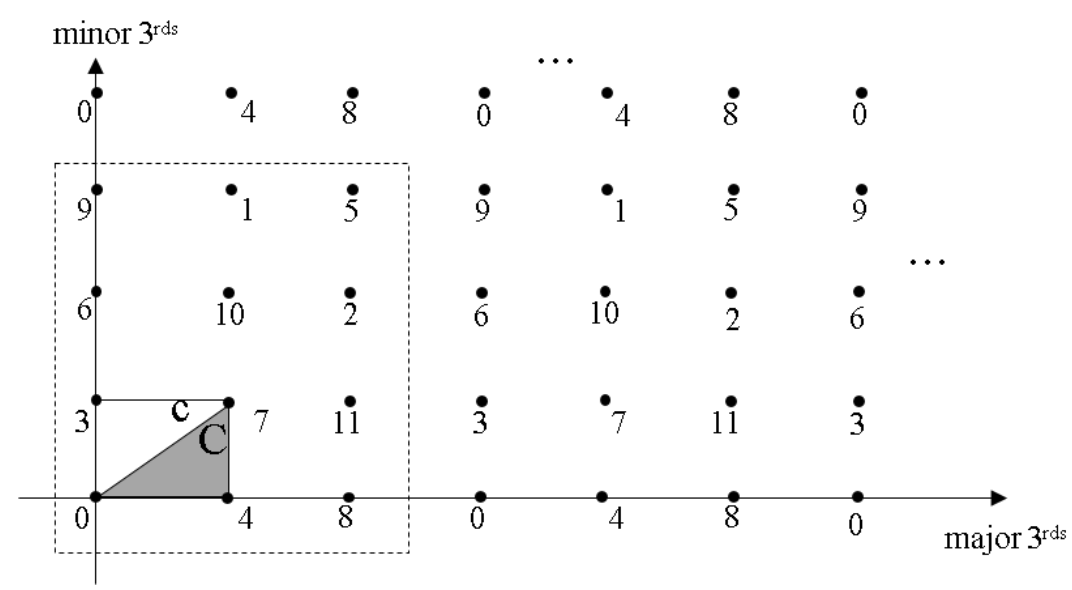

Figure 6. Tonnetz's basic structure: Major thirds (x axis) versus minor thirds (y axis). Points represent pitchclasses. Triangles represent major and minor triads. The dashed-line rectangle delimits the chromatic space.

This sort of structure is used for the plotting of k-ops (with the obvious exception of "I") as geometric vectors. For reasons of visual clarity, Figure 7 distributes the operations (considering $\mathrm{C}$ as referential triad) according to four classes of intervallic relationships (the black circles inside the triangles are positioned at their respective centroids): (a) diatonic thirds ( $\mathbf{r}$ and $\mathbf{R}$ ), (b) unison and minor second ( $\mathbf{P}$ and $\mathbf{S}$ ), (c) fifths (D and $\mathbf{F}$ ), (d) chromatic thirds ( $\mathbf{M}$ and $\mathbf{m}$ ). From this, a general overview of the system can be obtained by concentrating the vectors' origins at a single point, in this case representing a major referential triad (e). 
(a)

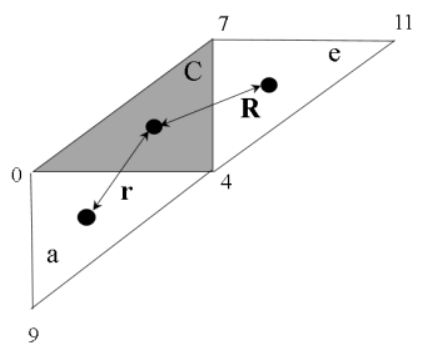

(c)

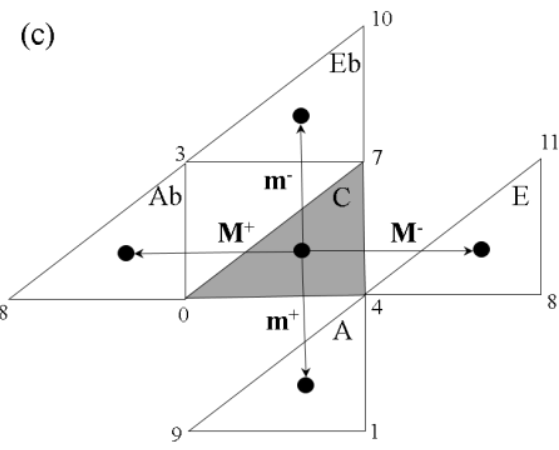

(b)

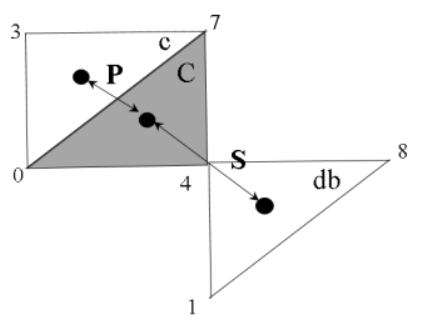

(d)

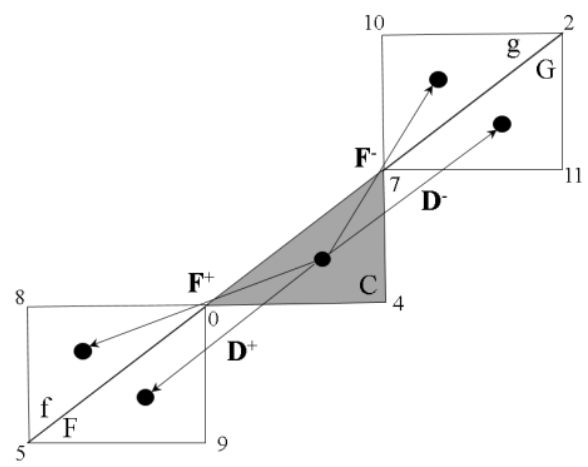

(e)

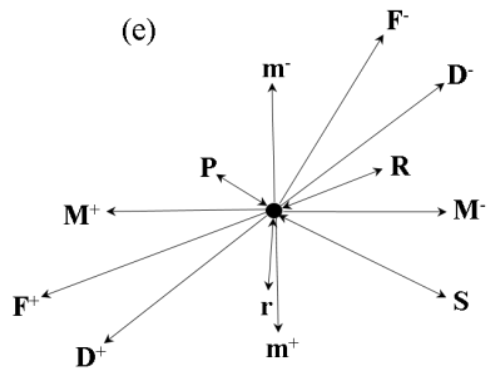

Figure 7. Geometric representation of the k-op's system, referring to the triad $\mathrm{C}$ and distributed into four pairs of operations: $\mathbf{r}$ and $\mathbf{R}$ (a); $\mathbf{P}$ and $\mathbf{S}$ (b); $\mathbf{D}$ and $\mathbf{F}$ (c); $\mathbf{M}$ and $\mathbf{m}$ (d). Concentration of the $12 \mathrm{k}$-ops at a single referential point, representing a major triad (e). Double arrows indicate commutative operations.

Since the modules of the vectors have no special relevance to the objectives of this study (contrary to what happens with their directions), they were circumscribed in unit circles (referring to a major (a) and a minor triads (b), in Figure 8), formatted as "compass roses" with four quadrants: "northeast", "southeast", "southwest" and "northwest". The vectors' angles, measured according to the routes "north" and "south", were calculated through trigonometric relations. 

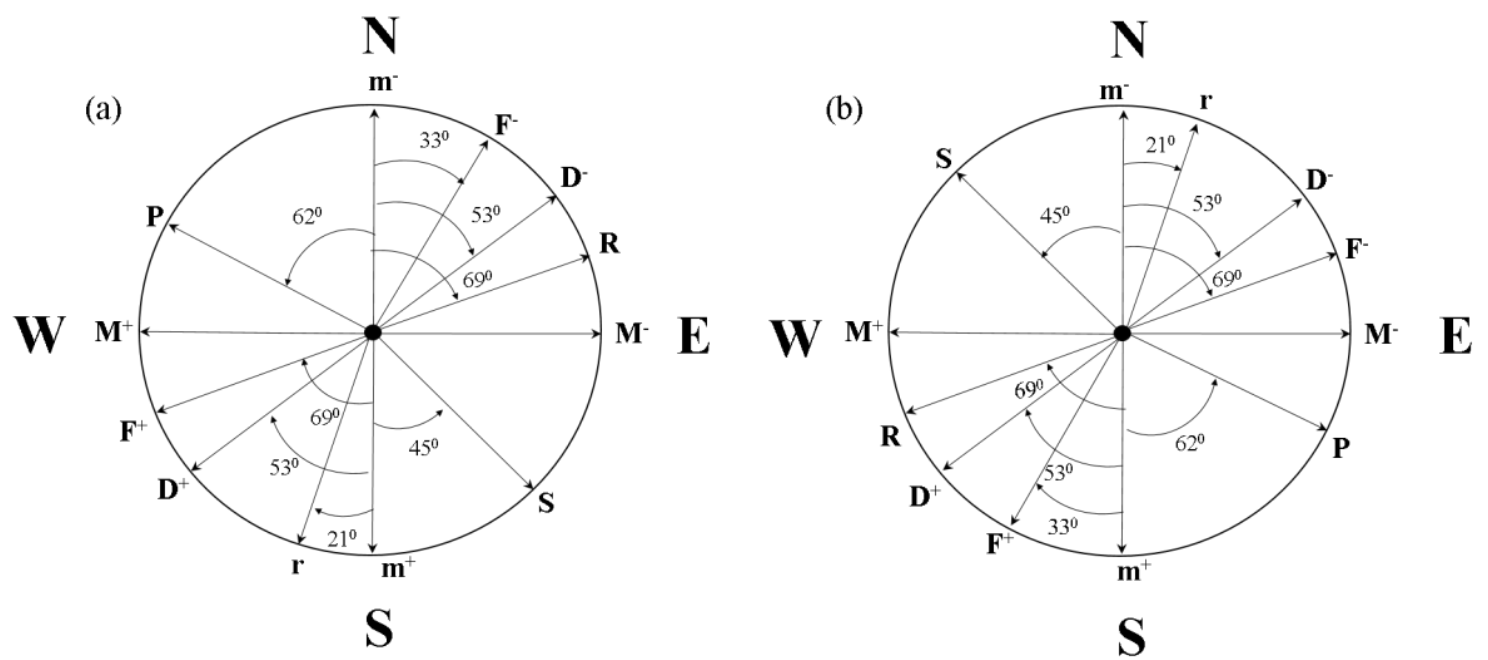

Figure 8. Major (a) and minor (b) "compass roses", informing the angles formed by vectors G and directions N or S.

The algebraic representation of vector G consists of a sequence of 11 entries, distributed into two sections: (i) destined to determine the four basic orthogonal routes: "north" (N), "south" (S), "east" (E) and "west" (W);4 (ii) dedicated to inform, in binary code, the angle (in degrees) which is formed between the vector and its respective basic route ( $\mathrm{N}$ or $\mathrm{S}$ ), being measured clockwise (E) or counterclockwise (W). Figure 9 shows the generic structure of G (a), a possible example (b) and its geometric representation (c).

$$
\begin{array}{c:c}
\text { (a) routes } & \multicolumn{1}{c}{\text { angle }} \\
\hdashline \mathrm{N} \mathrm{E} \mathrm{W} & x_{1} x_{2} x_{3} x_{4} x_{5} x_{6} x_{7}> \\
\text { (i) } & \text { (ii) (where } x_{n}=0 \text { or } 1 \text { ) }
\end{array}
$$

$$
\text { (b) }<\underbrace{1010}_{\mathrm{NE}} \underbrace{1000101>}_{69^{\circ}}
$$

(c) $\mathrm{N}$

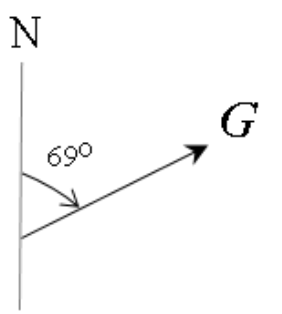

Figure 9. Generic structure of G (a), an example (b) with geometric representation (c).

The definitive chart of vector representation of Kopp's chromatic transformational system is shown in Figure 10, with the inclusion of information related to G. 


\begin{tabular}{|c|c|c|c|c|c|c|}
\hline symbol & triad a & triad b & $\mathbf{K}$ & $\mathrm{kc}$ & G & route \\
\hline $\mathbf{I}$ & $\mathrm{C}$ & $\mathrm{C}$ & $<00111111>$ & 63 & \multirow{2}{*}{$<00000000000>$} & \multirow{2}{*}{ (none) } \\
\hline I & $\mathrm{c}$ & $\mathrm{c}$ & $<11111111>$ & 255 & & \\
\hline $\mathbf{r}$ & $\mathrm{C}$ & $\mathrm{a}$ & $<01110011>$ & 115 & $<01010010101>$ & $21 \mathrm{SW}$ \\
\hline $\mathbf{r}$ & $\mathrm{c}$ & $\mathrm{E}_{b}$ & $<10110011>$ & 158 & $<10100010101>$ & 21NE \\
\hline $\mathbf{R}$ & $\mathrm{C}$ & $\mathrm{e}$ & $\langle 01011110\rangle$ & 94 & $<10101000101>$ & $69 \mathrm{NE}$ \\
\hline $\mathbf{R}$ & $\mathrm{c}$ & $\mathrm{A} b$ & $<10011110\rangle$ & 179 & $<01011000101>$ & $69 \mathrm{SW}$ \\
\hline $\mathbf{P}$ & $\mathrm{C}$ & $\mathrm{c}$ & $<01101101>$ & 109 & $\langle 10010111110\rangle$ & $62 \mathrm{NW}$ \\
\hline $\mathbf{P}$ & $\mathrm{c}$ & $\mathrm{C}$ & $<10101101>$ & 173 & $<01100111110\rangle$ & $62 \mathrm{SE}$ \\
\hline $\mathbf{S}$ & $\mathrm{C}$ & $\mathrm{d}_{b}$ & $<01010010\rangle$ & 82 & $<01100101101>$ & $45 \mathrm{SE}$ \\
\hline $\mathbf{S}$ & $\mathrm{c}$ & $\mathrm{B}$ & $<10010010\rangle$ & 146 & $<10010101101>$ & $45 \mathrm{NW}$ \\
\hline $\mathrm{D}^{+}$ & $\mathrm{C}$ & $\mathrm{F}$ & $<00100001>$ & 33 & \multirow{2}{*}{$<01010110101>$} & \multirow{2}{*}{$53 \mathrm{SW}$} \\
\hline $\mathbf{D}^{+}$ & $\mathrm{c}$ & $\mathrm{f}$ & $<11100001>$ & 225 & & \\
\hline $\mathbf{D}^{-}$ & $\mathrm{C}$ & $\mathrm{G}$ & $<00001100\rangle$ & 12 & \multirow{2}{*}{$<10100110101>$} & \multirow{2}{*}{$53 \mathrm{NE}$} \\
\hline $\mathbf{D}^{-}$ & $\mathrm{c}$ & $g$ & $<11001100\rangle$ & 204 & & \\
\hline $\mathbf{F}^{+}$ & $\mathrm{C}$ & $\mathrm{f}$ & $<01100001>$ & 97 & $<01011000101>$ & $69 \mathrm{SW}$ \\
\hline $\mathbf{F}^{+}$ & $\mathrm{c}$ & $\mathrm{F}$ & $<10100001>$ & 161 & $<10010100001>$ & $33 \mathrm{NW}$ \\
\hline $\mathbf{F}^{-}$ & $\mathrm{C}$ & $\mathrm{g}$ & $<01001100\rangle$ & 76 & $<10100100001>$ & $33 \mathrm{NE}$ \\
\hline $\mathbf{F}^{-}$ & $\mathrm{c}$ & $\mathrm{G}$ & $<10001100>$ & 140 & $<10101000101>$ & $69 \mathrm{NE}$ \\
\hline $\mathbf{M}^{+}$ & $\mathrm{C}$ & $\mathrm{A} b$ & $<00100010\rangle$ & 34 & \multirow{2}{*}{$<00010000000\rangle$} & \multirow{2}{*}{ ow } \\
\hline $\mathbf{M}^{+}$ & $\mathrm{c}$ & $\mathrm{a} b$ & $<11010001>$ & 209 & & \\
\hline $\mathbf{M}^{-}$ & $\mathrm{C}$ & $\mathrm{E}$ & $<00010100\rangle$ & 20 & \multirow{2}{*}{$<00100000000>$} & \multirow{2}{*}{$0 \mathrm{E}$} \\
\hline $\mathbf{M}^{-}$ & $\mathrm{c}$ & $\mathrm{e}$ & $<11001010\rangle$ & 202 & & \\
\hline $\mathbf{m}^{+}$ & $\mathrm{C}$ & $\mathrm{A}$ & $<00010001>$ & 17 & \multirow{2}{*}{$<01000000000>$} & \multirow{2}{*}{$0 \mathrm{~S}$} \\
\hline $\mathbf{m}^{+}$ & $\mathrm{c}$ & $\mathrm{a}$ & $<11100010\rangle$ & 226 & & \\
\hline $\mathbf{m}^{-}$ & $\mathrm{C}$ & $\mathrm{E}_{b}$ & $\langle 00001010\rangle$ & 10 & \multirow{2}{*}{$<10000000000>$} & \multirow{2}{*}{$0 \mathrm{~N}$} \\
\hline $\mathbf{m}^{-}$ & $\mathrm{c}$ & $\mathrm{eb}$ & $<11010100\rangle$ & 212 & & \\
\hline
\end{tabular}

Figure 10. Vector representation of the k-ops, considering symbols, referential and de-rived triads (examples in $\mathrm{C}$ and $\mathrm{c}$ ), binary contents of $\mathrm{K}$, k-code, binary contents of $\mathrm{G}$, angular directions.

Observations:

- Operation I can be considered as null-vector, therefore its module is equal to zero and it is not possible to establish a formal direction (or an angle) on the Tonnetz;

- Operations $\mathbf{r}, \mathbf{R}, \mathbf{P}$, and $\mathbf{S}$ are major-minor distinct considering both the content of their vectors $G$ and the routes of their angles, which highlights the commutative property that they share. Operation $\mathbf{F}$ is major-minor distinct in relation to the angles/routes. The remaining k-ops behave equally regardless the mode of the referential triad.

\section{4 - Analytical Applications}

A computational program recently implemented in Matlab, named Tonnetz-Kopp uses both vectors as distinct analytical approaches of triadic transformation. Vector $\mathrm{K}$ is employed for determining which is the operation that connects each couple of triads entered as input. Figure 11 describes the basic steps of the algorithm responsible for this task, using the chord progression "F-A" as example: (1) the user enters the alphabetic labels of the triads; (2) the program transcribes the labels to pc-sets in triadic normal form with the aid of a pre-installed 
chord lexicon; (3) the modes of the both chords are then determined as well as the first section of $\mathrm{K}$; (4) the algorithm searches correspondences between the pcs of both sets, whose positions are then identified. ${ }^{5}$ The second section of $\mathrm{K}$ is then filled in; (5) the content of $\mathrm{K}$ is transcribed in decimal format (kc), which allows the program to return the corresponding k-op label.

1. Enter alphabetic labels of triads $a$ and $b: \quad \mathrm{F} \quad \mathrm{a}$

2. Transcribe alphabetic labels as pc's sets in normal form: chord LEXICON $\left\{\begin{array}{l}\mathrm{F}=[5,9,0] \\ \mathrm{A}=[9,1,4]\end{array}\right.$

3. Find the modes of the both triads by subtraction $\left(a_{3}-a_{1}\right.$ and $\left.b_{3}-b_{1}\right)$, using Mod12; transpose the results to $K$ :

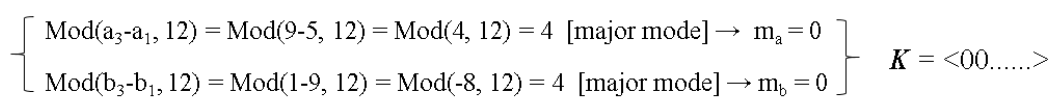

4. Search for mappings of notes/positions of triad $a$ in triad $b$; complete $K$ :

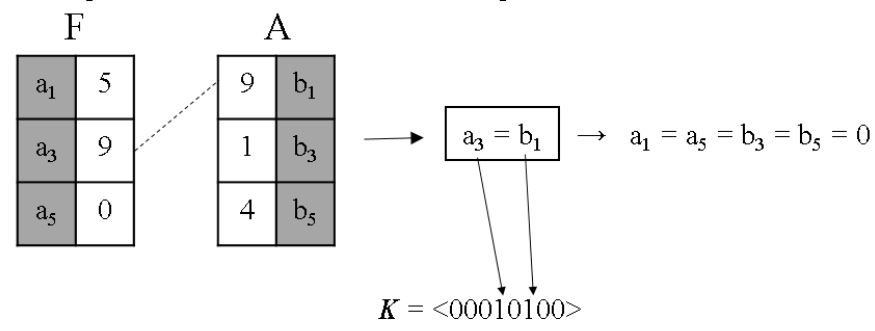

5. Transcribe the content of $K$ as decimal format to find its corresponding "kc"; with the result determine the class of k-op:

$$
\mathrm{kc}=\operatorname{bin} 2 \operatorname{dec}(00010100)=20 \rightarrow \mathrm{M}^{-}
$$

Figure 11. Schematic description of Tonnetz-Kopp's analytical algorithm.

Vector $\mathrm{G}$ provides a general overview of the spatial trajectories which result from the geometric projections of the k-ops. This function uses as input the code kc, referred to an operation returned by the analytical algorithm. This allows to retrieve the operation's corresponding vector $\mathrm{G}$ and, consequently, its associated geometric route and angle. A specific function uses these data for plotting a trajectory which represents essentially harmonic paths on the Tonnetz plan. Figure 12 presents an example of application of both vectors in the transformational analysis of the first part of the Broadway's song All the Things You Are, composed by Jerome Kern and Oscar Hammerstein II. ${ }^{6}$

\footnotetext{
${ }^{5}$ If no mappings can be found, there is no common note and, consequently, the connection is not made through a unique k-op. In this case the program "breaks" the progression in two parts, assigning an intermediary triad $c$ (a sort of "bridge-chord") with common notes with triads $a$ and $b$. Triad $c$ takes then the place of triad $b$ and the algorithm is applied, returning the corresponding $\mathrm{k}$-op. The process is applied again, this time between triads $c$ and $b$. As a definitive resulting, triads $a$ and $b$ are connected by a sequence of two k-ops.

${ }^{6}$ For the sake of simplicity, the seventh-chords present in the song were reduced to their triadic structures.
} 
(a)

(b)

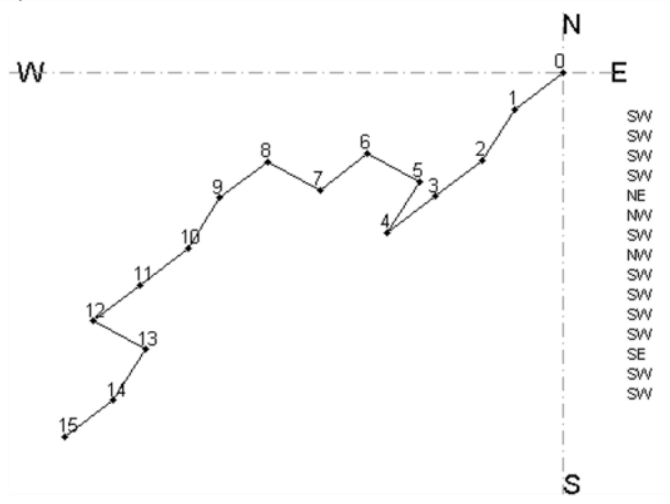

\begin{tabular}{l|l|l|l|}
\hline & & & \\
\hline & LEVEL 2 \\
\hline
\end{tabular}
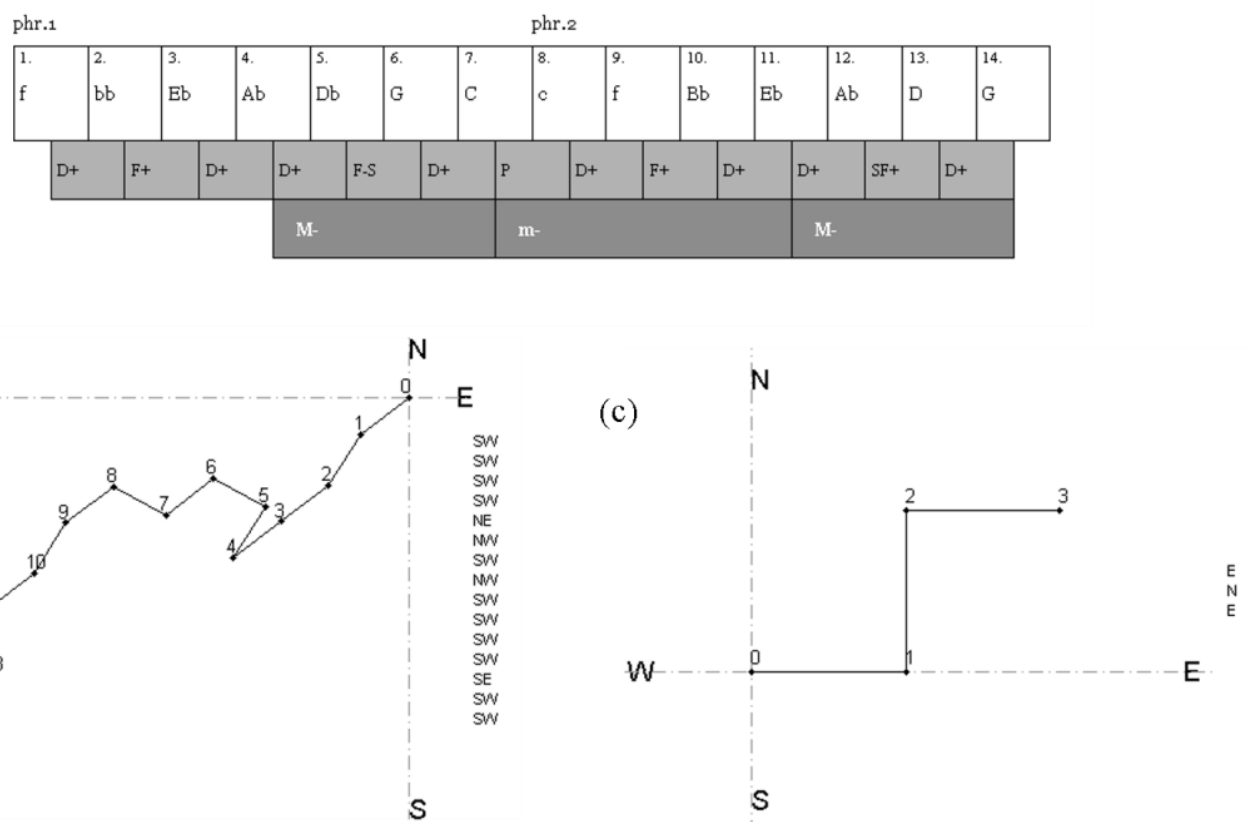

Figure 12. Transformational analysis of the first part of All the Things You Are(mm.1-16), by J. Kern and 0. Hammerstein II, using vectors K and G: (a) k-ops connecting contiguous chords (level 1) and chords in phrase boundaries (level 2); (b) trajectory corresponding to k-ops of level 1 and (c) trajectory corresponding to k-ops of level 2. Graphs produced by the program Tonnez-Kopp.

\section{5 - Concluding Remarks}

The complementary concepts introduced in this study aim to contribute for the formalization of some aspects of the Neo-Riemannian / Transformational theories. While the algebraic representation of vector $\mathrm{K}$ provides a precise and compact description of the processes associated to a given transformational operation, vector G, through both content and spatial representation, opens up an interesting perspective addressing the investigation of meaning of tonal directions. By hypothesis, the distinct trajectories resulting from the concatenation of $\mathrm{k}$ ops would be intimately linked to constructive strategies (and, perhaps, to stylistic characteristics, composer's preferences, etc.), which will be examined in further studies. Same paragraph? Though in an initial stage and still requiring some tests and improvements, the implementation of the vector representation in the computational program Tonnetz-Kopp can be considered plainly successful.

\section{References}

1. COHN, Richard. (1998). Introduction to Neo-Riemannian Theory: A Survey and a Historical Perspective. Journal of Music Theory, n.42, v.2, p.167-180.

2. (2012). Audacious Euphony: Chromatic Harmony and the Triad's Second Nature. Oxford: Oxford University Press. 
3. DOUTHETT, Jack and STEINBACH, Peter. (1998). Parsimonious Graphs: A Study in Parsimony, Contextual Transformations, and Modes of Limited Transposition. Journal of Music Theory, n. 42, v. 2, p.241-263.

4. HYER, Brian. (1995). Reimag(ing) Riemann. Journal of Music Theory, n.39, v.1, p.101-138.

5. KOPP, David. (2002). Chromatic Transformations in Nineteenth-Century Music. New York: Cambridge University Press.

6. LEWIN, David. (1982). A Formal Theory of Generalized Tonal Functions. Journal of Music Theory, n.26, v.1, p.23-60.

7. RIEMANN, Hugo. (1896). Harmony Simplified. London: Augener (1896).

8. TYMOCZKO, Dmitri. (2011). A Geometry of Music: Harmony and Counterpoint in the Extended Common Practice. Oxford: Oxford University Press.

Note about the author

Carlos de Lemos Almada is PhD in Music and Professor at the School of Music of the University Federal of Rio de Janeiro. His main research interests are centered on Schoenberg's music, Grundgestalt and developing variation theories, Neo-Riemannian analysis, structural studies on popular music and computational-assisted analyzes and composition. He has published several papers in scientific journals and in international conference proceedings. Almada is member of the Brazilian Association of Theory and Music Analysis, leader of the MusMat Research Group and member of the editorial board of Brazilian Journal of Music and Mathematics and Musica Theorica. Composer and arranger, Almada is also author of five books: Arranjo (2001), A Estrutura do Choro (2006), Harmonia Funcional (2009), Contraponto em Música Popular (2013) and Nas Fronteiras da Tonalidade (2016). 